by Gary B. Lewis

\title{
EarthCaching - An Earth science outreach success story
}

\author{
Director, Education \& Outreach, The Geological Society of America, Boulder Colorado, USA. E-mail: glewis@ geosociety.org
}

\begin{abstract}
EarthCaching is a real success story in how Earth science can benefit by working with successful community programs that link self-learning, technology, and the thrill of outdoor adventure. With over 11,000 Earth science sites worldwide visited by 1.3 million people, it is making a real impact toward bringing Earth science to the wider community.
\end{abstract}

Engaging the public in geoscience is always a challenge. What is even more of a challenge is having them experience geology in the field with nothing more than a few pages of notes. And yet EarthCaching (www.earthcache.org) has them doing exactly thatat over 10,000 sites around the globe.

EarthCaching, a program developed and coordinated by the Geological Society of America (GSA), is part of the highly successful worldwide treasure-hunt phenomenon known as geocaching. The game is based around the use of a GPS receiver (GPSr) to find a location at which other people have hidden a container. In the container can be found a log book and in many small treasures to trade. The visitor signs the log book, trades a trinket, then re-hides the container in the same place. Afterward, they log the experience online. In EarthCaching, however, there is no container-Earth itself provides the treasure. Visitors to EarthCaches are asked to undertake an educational Earth-science based task to both expand their own knowledge and to prove that they visited the site. They then log their visit on the geocaching website.

EarthCaching started in 2003 when a GSA member mentioned at a meeting that GSA should somehow get involved in geocaching. Within a few months, GSA partnered with the geocaching company Groundspeak Inc., and the U.S. National Park Service established a set of guidelines for the creation of EarthCaches, setting up three trial sites. From these three, one in Australia and two in Colorado and with the help of many hundreds of individual cachers, there are now well over 10,000 EarthCache sites in 135 countries. These sites have been visited by over 1.3 million people, and the number is rising exponentially.

EarthCaches can be developed by anyone in the community through the geocaching website (www.geocaching.com) using the following guidelines:

1. EarthCache sites must provide Earth science lessons: They take people to sites that can help explain the formation of landscapes, or to sites of interesting phenomena, such as folds, faults, intrusions, or to sites that reveal how scientists understand our Earth (such as fossil sites etc).
2. EarthCache sites must be educational: They provide accurate but simple explanations of what visitors will experience at the site. Cache text must assume no previous knowledge of Earth science. The educational notes must be written to a reading age of an upper middle school (14 year old) student. Avoid direct plagiarism from web sources, and quote sources of information where appropriate. Additional technical or scientific notes can be provided for the scientific community at the end of the listing. All notes must be submitted in the local language.

3. EarthCache sites can be a single site or a multiple virtual cache: No items, boxes, or physical caches can be left at the site. You must have visited the site recently (within two months), checked the site is safe, and taken multiple GPS readings to ensure the accuracy of your coordinates. You are responsible for disabling an EarthCache if access or safety conditions change.

4. EarthCaches should highlight a unique feature: EarthCaches that duplicate existing EarthCache information about the site or related sites may be rejected. EarthCaches should be developed to provide a unique experience to the visitor. Multiple EarthCaches on the same feature should be avoided, and content rather than proximity will be the guiding principle.

5. EarthCache sites follow geocaching principles and also adhere to the principles of Leave No Trace outdoor ethics: Use waypoints to ensure cachers take appropriate pathways. Use established trails only do not create new trails to a site in order to concentrate use impacts. EarthCache sites will highlight the principle of collecting photos-not samples. However, if there is no possible damage to a site that is outside of the public land system and approved by the site owner, small samples may be collected as part of the cache experience.

6. Logging of an EarthCache must involve visitors undertaking some educational task that relates to the earth science at the site. This could involve measuring or estimating the size of some feature or aspect of the site, collecting and recording data (such as time of a tidal bore), or sending an e-mail to the cache owner with the answer to earth science-related questions obtained by reading an information display at the site. While photographs may be requested, they do not take the place of other logging requirements. Taking a photograph alone or asking people to do Internet research does NOT meet these logging guidelines. Requests for specific content in the photograph (must include the visitor's face, for example) will be considered an additional logging requirement and must be optional. Cache owners may 


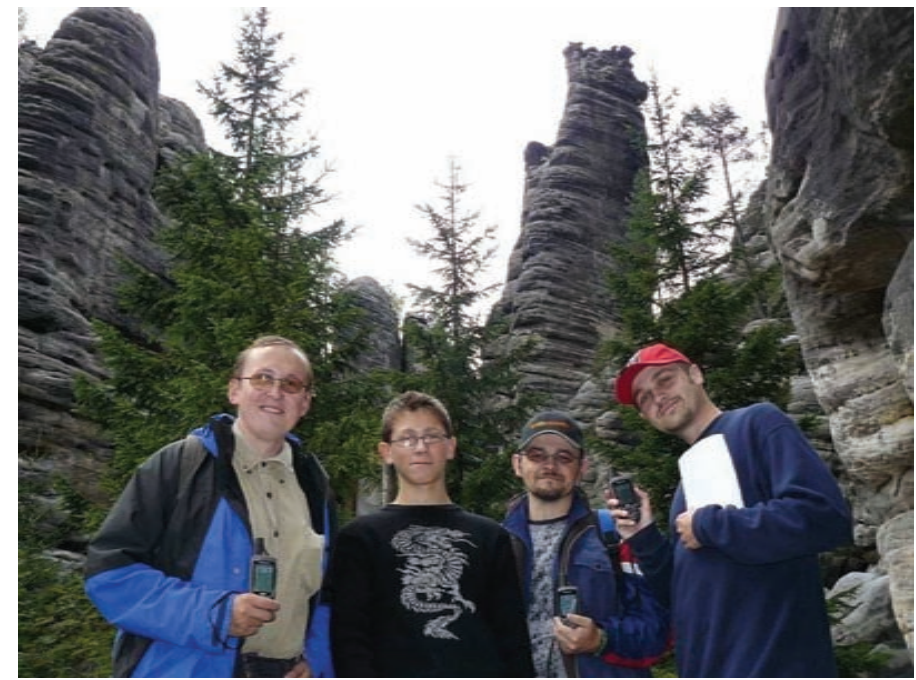

Visitors at the Rock Walls EarthCache in Kralovehradecky kraj, Czech Republic

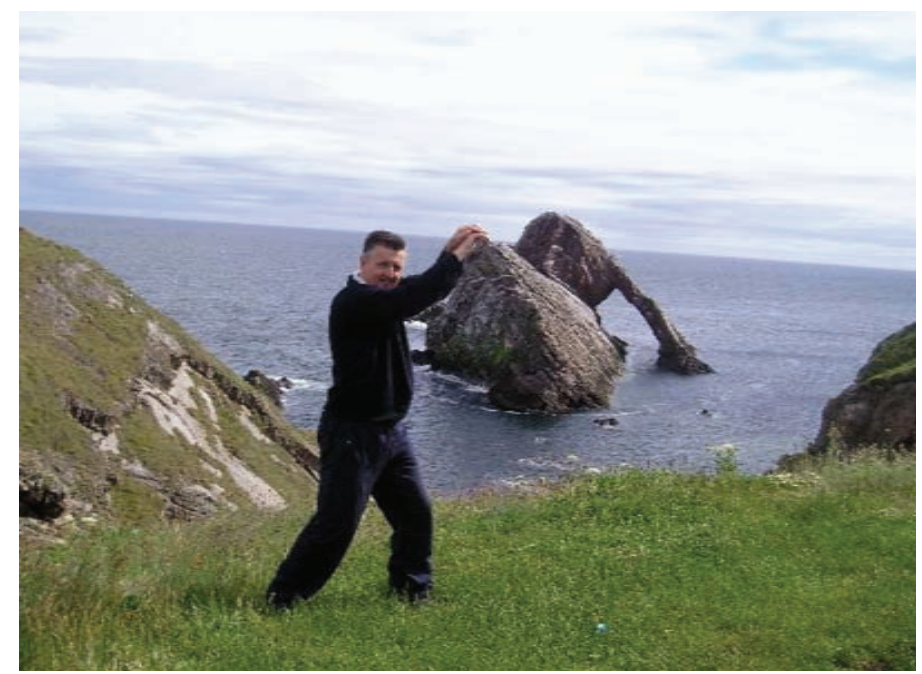

EarthCaching can provide great photo opportunities, here at Bow Fiddle Rock in the UK.

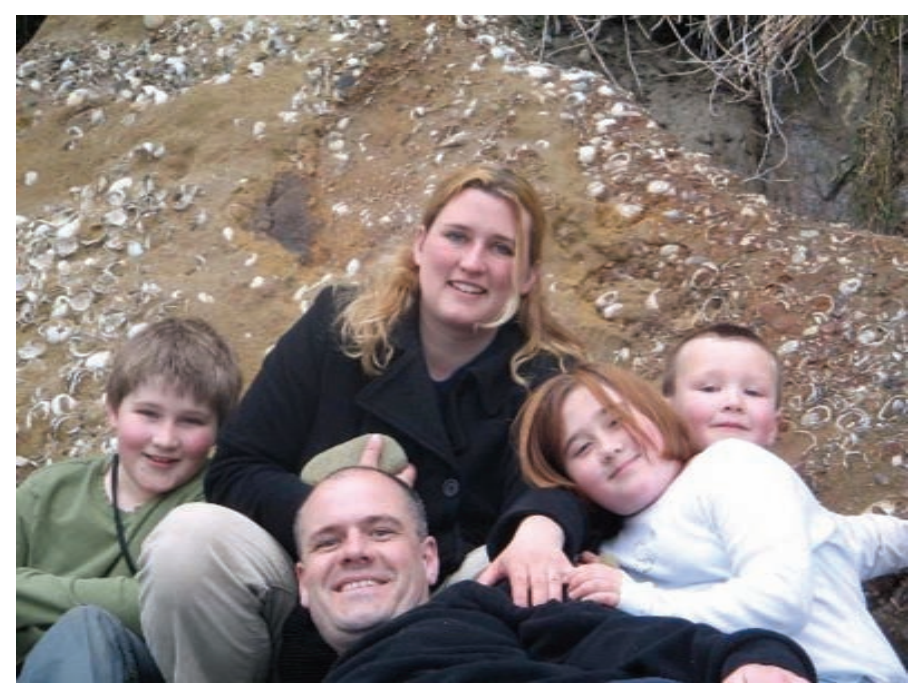

What better way to get children involved in geoscience than visiting fossil bed, here in BC, Canada.

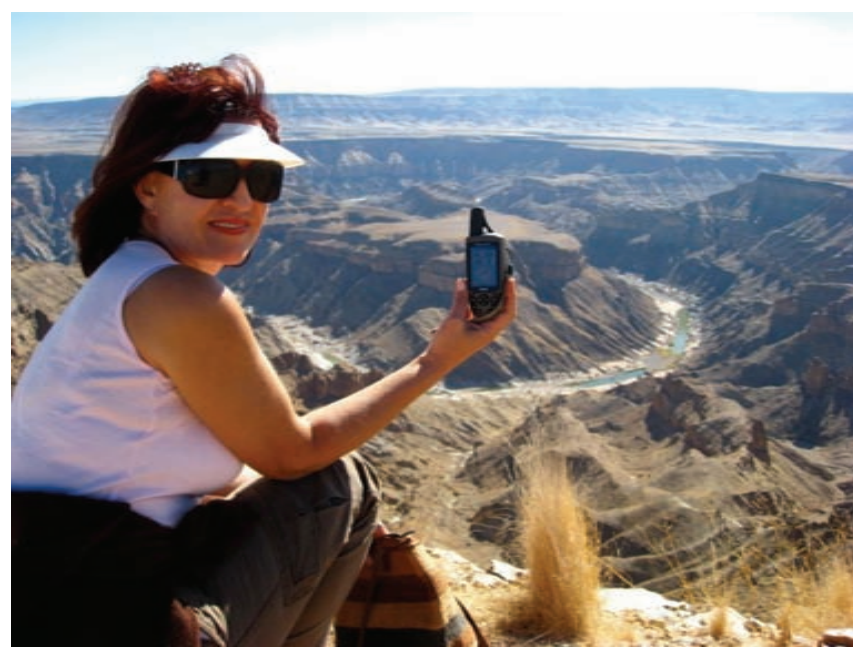

EarthCacher "Pussycat" at the Fish River Canyon in Namibia

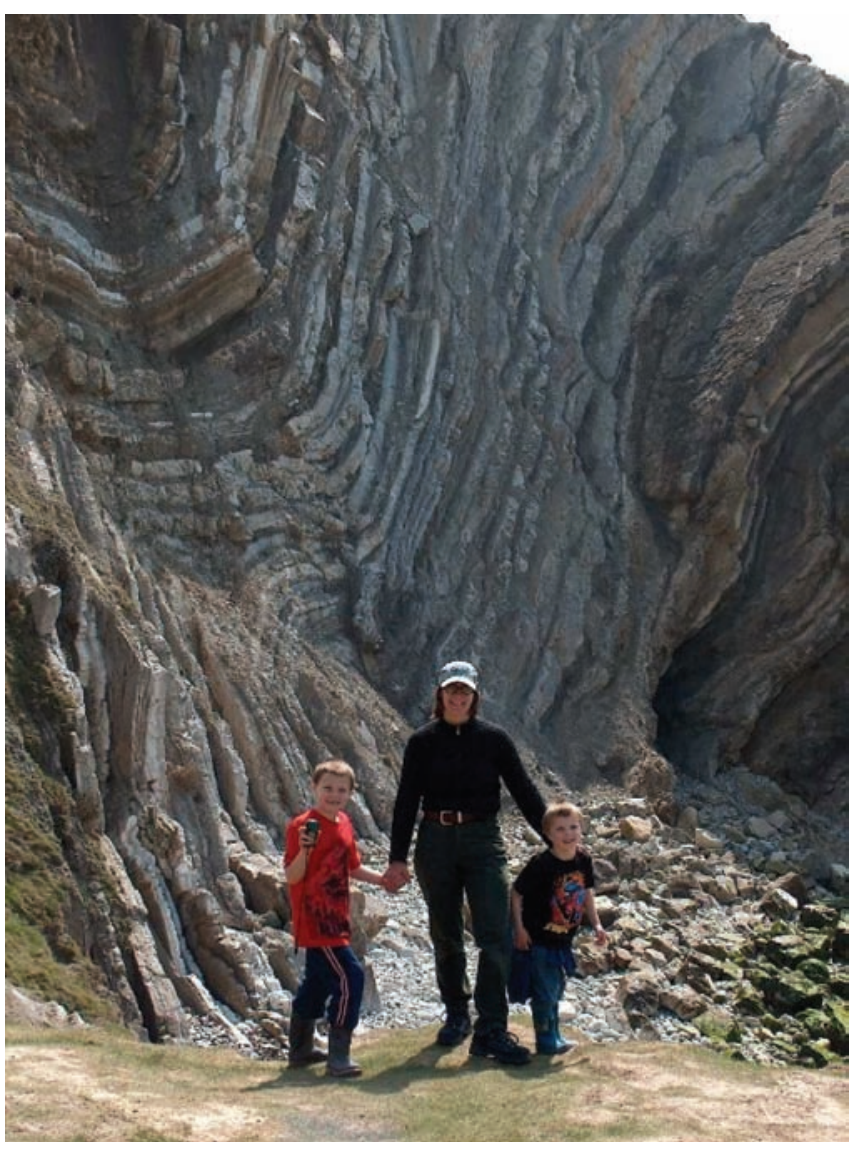

Young EarthCachers take their mother to an Earthcache in Dorset, UK 
not delete the cache seeker's log based solely on optional tasks.

7. All EarthCache sites must have prior approval of the landowners before submission (depending on local country laws and customs). When applicable, you must have written approval from the appropriate owner or land-managing agency.

8. Damage to the site is unacceptable: Please be mindful of fragile ecosystems.

These guidelines are evolving; EarthCache developers are asked to check the latest guidelines before submitting a new site. Full guidelines are at www.earthcache.org.

Each submission is reviewed by a team of EarthCache reviewers, and if the site meets the guidelines, the team publishes the listing. This peer review ensures the quality and appropriateness of all EarthCaches.

In 2009 a review of the then-existing published EarthCaches (around 6,500 sites) by a peer team highlighted ten of the very best EarthCaches around the world. The list, published at www. earthcache.org, is a great starting place for someone who wants to develop an EarthCache to see what best practice in development looks like.

While no formal evaluation of the EarthCache program has been undertaken, anecdotal evidence suggests that the vast majority of the people who visit have no geoscience background, and a large number of the developers of sites also have little formal post-secondary geoscience education. However, these people do a wonderful job of researching and developing sites for publishing.

In addition to the wonder of finding an Earthcache site and then undertaking an educational task, participants are also encouraged to join the EarthCache Masters program, to be rewarded with icons for levels of participation (Bronze, Silver, Gold, and Platinum). This program, supported by Subaru of America, Inc., has been a highly successful tool in encouraging people to participate. Over 12,300 icons have been awarded so far, and over 840 people have reached the Platinum EarthCache Master level.

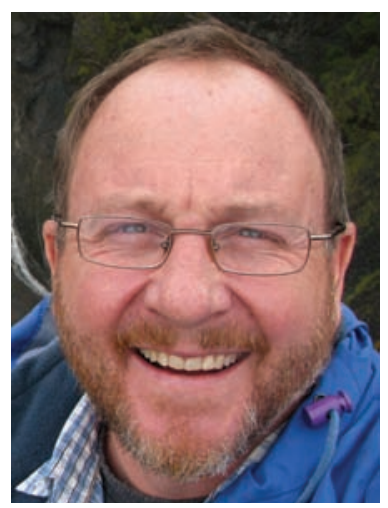

Gary Lewis studied his BS degree in Geology at the University of Sydney, Australia, with the aim of becoming an Earth science teacher. After a few years in the classroom, he joined CSIRO's Education Programs and then established the education efforts at the Australian Geological Survey Organisation (now GeoScience Australia). In 2003, he began working for the Geological Society of America as the Director of Education \& Outreach and works on a number of successful global education programs. He has been the chair of the IUGS Commission on Geocience Education, Training and Technology Transfer (COGE) and is working on the IUGS Strategic Planning Committee. He lives and works in Maine, USA. 